\title{
Comparison of Oral Acetaminophen Versus Ibuprofen in Premature Infants With Patent Ductus Arteriosus
}

\author{
Mohammad Mehdi Bagheri, ${ }^{1}$ Pedram Niknafs, ${ }^{1}$ Fatemeh Sabsevari, ${ }^{1,}{ }^{*}$ Mohammad Hosein Torabi, \\ Bahareh Bahman Bijari, ${ }^{1}$ Elahe Noroozi, ${ }^{1}$ and Hamid Mossavi ${ }^{1}$ \\ ${ }^{1}$ Afzalipour Medical Center, Kerman University of Medical Sciences, Kerman, IR Iran \\ "Corresponding author: Fatemeh Sabsevari, Afzalipour Medical Center, Kerman University of Medical Sciences, Kerman, IR Iran. Tel: +98-9131951947, E-mail: \\ fasabzvari@gmail.com
}

Received 2015 October 30; Revised 2016 January 28; Accepted 2016 February 05.

\begin{abstract}
Background: Patent ductus arteriosus (PDA) is a common cause of morbidity. The aim of this study was to compare the efficacy of oral Acetaminophen and oral Ibuprofen for the closure of patent ductus arteriosus (PDA) in preterm infants.

Objectives: This study demonstrated that, there was no significant difference between treatment of PDA with either oral Acetaminophen or oral Ibuprofen in preterm neonates.

Patients and Methods: This clinical trial, randomized study, enrolled 120 infants, with a gestational age of $<37$ weeks, who were admitted in neonatal intensive care unit of Afzalipour hospital, Kerman, Iran, in 2014. PDA was confirmed echocardiographically. The trial was registered in Iranian registry of clinical trials (Reg. No. 25542). Sixty-seven infants received oral Acetaminophen (15mg/kg every six hours for three days) and 62 infants received Ibuprofen (an initial dose of $20 \mathrm{mg} / \mathrm{kg}$, followed by $10 \mathrm{mg} / \mathrm{kg}$ at 24 and 48 hours). To evaluate the efficacy of the treatment, a second echocardiography was done after completing the treatment.

Results: After the first course of the treatment, PDA closed in 55 (82.1\%) patients who received oral Acetaminophen vs. 47 (75.8\%) of those given oral Ibuprofen $(\mathrm{P}=0.38)$. After the second course of treatment, PDA closed in $50 \%$ of oral Acetaminophen group and 73.3\% of oral Ibuprofen group $(\mathrm{P}=0.21)$.

Conclusions: This study demonstrated that, there was no significant difference between treatment of PDA with either oral Acetaminophen or oral Ibuprofen in preterm neonates. Oral Ibuprofen can effectively close PDA but is unfortunately associated with some adverse effects limiting its utility thus we studied an alternative drug with similar efficacy and less adverse effects. This study has recommends Acetaminophen with minimal complications for the treatment of PDA in preterm neonates instead of Ibuprofen.
\end{abstract}

Keywords: Patent Ductus Arteriosus (PDA), Neonatal Intensive Care Unit (NICU), Acetaminophen, Ibuprofen, Echocardiography

\section{Background}

Patent ductus arteriosus (PDA) is common amongst preterm infants with an incidence of $30 \%$ in very low birth weight infants (Bwt $<1500 \mathrm{~g})(1)$ and $50 \%$ in extremely low birth weight ones (Bwt $<1000 \mathrm{~g}$ ) (2).

Subsequently, prolonged ductal patency in preterm infants was linked to more severe respiratory distress syndrome (RDS), prolonged assisted ventilation, pulmonary hemorrhage, bronchopulmonary dysplasia (BPD), necrotizing enterocolitis (NEC), renal impairment, intraventriculur-hemorrhage (IVH), periventricular leukomalacia (PVL), cerebral palsy, and death (3).

Taking these aforementioned associations into consideration, appreciation of the hemodynamic effects of a large left-to-right shunt through the ductus, and certain morbidities caused by excessive blood flow in the lungs or ischemia elsewhere led many practitioners to adopt strategies for closing the ductus.
Currently, the first choice of treatment for PDA is medical, primarily Indomethacin and Ibuprofen. These drugs are cyclooxygenase inhibitors, blocking the conversion of arachidonic acid to prostaglandins (4).

The treatment success with Ibuprofen for the management of PDA was reported between 70\% - 85\% (5).

The adverse effects such as peripheral vasoconstriction, gastrointestinal bleeding and perforation, decreased platelet aggregation, hyperbilirubinemia, and renal failure have been reported with cyclooxygenase inhibitors (6).

Acetaminophen acts by inhibiting the activity of prostaglandin synthase at the peroxidase region of the enzyme (7).

Recent studies have shown that Acetaminophen can be used to treat PDA in preterm infants with good efficacy and a few side effects, unlike cyclooxygenase inhibitors (8).

When drug treatment fails or is contraindicated, clinicians may resort to surgical intervention although the risk of operation in preterm infants is high. 
To determine whether oral Acetaminophen may be used as the first line or an alternative drug for PDA in preterm infants, we conducted a randomized trial to compare its efficacy and safety level to those of Ibuprofen.

\section{Objectives}

This study demonstrated that, there was no significant difference between treatment of PDA with either oral Acetaminophen or oral Ibuprofen in preterm neonates.

\section{Patients and Methods}

The study was performed in the neonatal intensive care unit (NICU) of Afzalipour medical center, Kerman, Iran between July and November, 2014.

This trial was approved by the ethics committee, and infants were enrolled in the study after parental consent was obtained.

The enrollment criteria included a gestational age of under 37 weeks, a postnatal age of less or equal to fourteen days and an echocardiographically diagnosed PDA following an echocardiographic detection of a duct size more than $1.5 \mathrm{~mm}$ and a left atrium to aorta ratio of more than 1.2.

The exclusion criteria were as follow: 1 , a major congenital heart disease; 2, confirmed sepsis; 3, intraventricular hemorrhage grade > II (IVH on the basis of Volpe staging); 4 , platelet count $<50000 / \mathrm{mm}^{3} ; 5$, severe coagulopathy or liver dysfunction; 6 , the presence of major congenital or chromosomal abnormalities; 7 , severe asphyxia at birth (Apgar score less than 5 in minute five or $\mathrm{pH}<7$ in $\mathrm{ABG}$ ); 8, necrotizing enterocolitis (NEC on the basis of Bell staging); 9, tendency to bleeding as revealed by hematuria, blood in the endotracheal or gastric aspirate or stools, or oozing from puncture sites; 10 , urine output $<1 \mathrm{~mL} / \mathrm{kg} /$ hour or serum creatinine $>1 / 6 \mathrm{mg} / \mathrm{dL}$; 11 , retionpathy of prematurity.

Before and after treatment, all patients were evaluated with complete blood count, serum creatinine, blood urea nitrogen, urine output, bilirubin levels, cranial ultrasonography and two-dimensional color Doppler echocardiography using a 4MH2 transducer (model: MEDISON ACCUVIIXV100, South Korea).

The participants were randomly assigned at a $1: 1$ ratio between oral Acetaminophen and Ibuprofen groups by using cards. Doctors and nurses were not blind but a pediatric cardiologist in charge of the patients was blinded to the treatment.

Infants received oral Acetaminophen (Acetaminophen suspension, Hakim, $5 \mathrm{~mL}: 120 \mathrm{mg}$ ) at the dose of $15 \mathrm{mg} / \mathrm{kg}$ every 6 hours for 3 days or oral Ibuprofen (Ibuprofen suspension, Exir $5 \mathrm{~mL}: 100 \mathrm{mg}$ ) at the initial dose of $20 \mathrm{mg} / \mathrm{kg}$ followed by $10 \mathrm{mg} / \mathrm{kg}$ after 24 and 48 hours.

Both Acetaminophen and Ibuprofen were administered via an orogastric-tube, which was flushed with 1 - 2 $\mathrm{mL}$ of sterile water to ensure delivery of the drug.

Minimal enteral feeding was attempted for all infants from the second day of life, and patients continued their current enteral feeding regimen during the study. At the beginning of the study, daily oral intake ranged between 10 and $60 \mathrm{~mL} / \mathrm{kg}$ for patients in both groups.

For all infants enrolled in the study, fluid intake was started at $60-80 \mathrm{~mL} / \mathrm{kg} /$ day, consistently for three days and after that, it was increased by increments of $20 \mathrm{~mL} / \mathrm{kg} /$ day, to a maximum of $150 \mathrm{~mL} / \mathrm{kg} /$ day.

During the treatment, drug safety factors were assessed daily. If birth weight was less than $2 \mathrm{~kg}$ an eye examination was conducted 4 weeks after birth. Occurrence of any exclusion criteria would prompt stopping of treatment.

The success rate was defined as a closed duct on echocardiography after the complete course of both drugs.

Secondary outcomes were the safety of both drugs, and adverse events (e.g. oliguria, IVH, tendency to bleeding, NEC, death).

\subsection{Statistical Analyses}

A study group of at least 57 patients was needed for the study to facilitate detecting a difference of at least 25 percentage points in the closure rate between the oral Acetaminophen and Ibuprofen groups, assuming a closure rate of $85 \%$ with oral Ibuprofen with a $\mathrm{P}=0.05$ and a power of $50 \%$. The study would be terminated if a difference of $25 \%$ in the main outcome was found.

Continuous data were given as mean (SD). Differences between the groups were determined by t-test for parametric continuous data, or Fisher's exact test for categorical data.

A new drug is considered at least as effective as the known drug if $\mathrm{P}<0.05$ of the difference between the two groups. SPSS software (version 20) was used for all statistical analyses.

\section{Results}

Among 160 patients enrolled in our study which had significant PDA with inclusion criteria, finally 31 patients were excluded. The study flow chart is demonstrated in Figure 1. 
160 Preterm Infants with Significant PDA
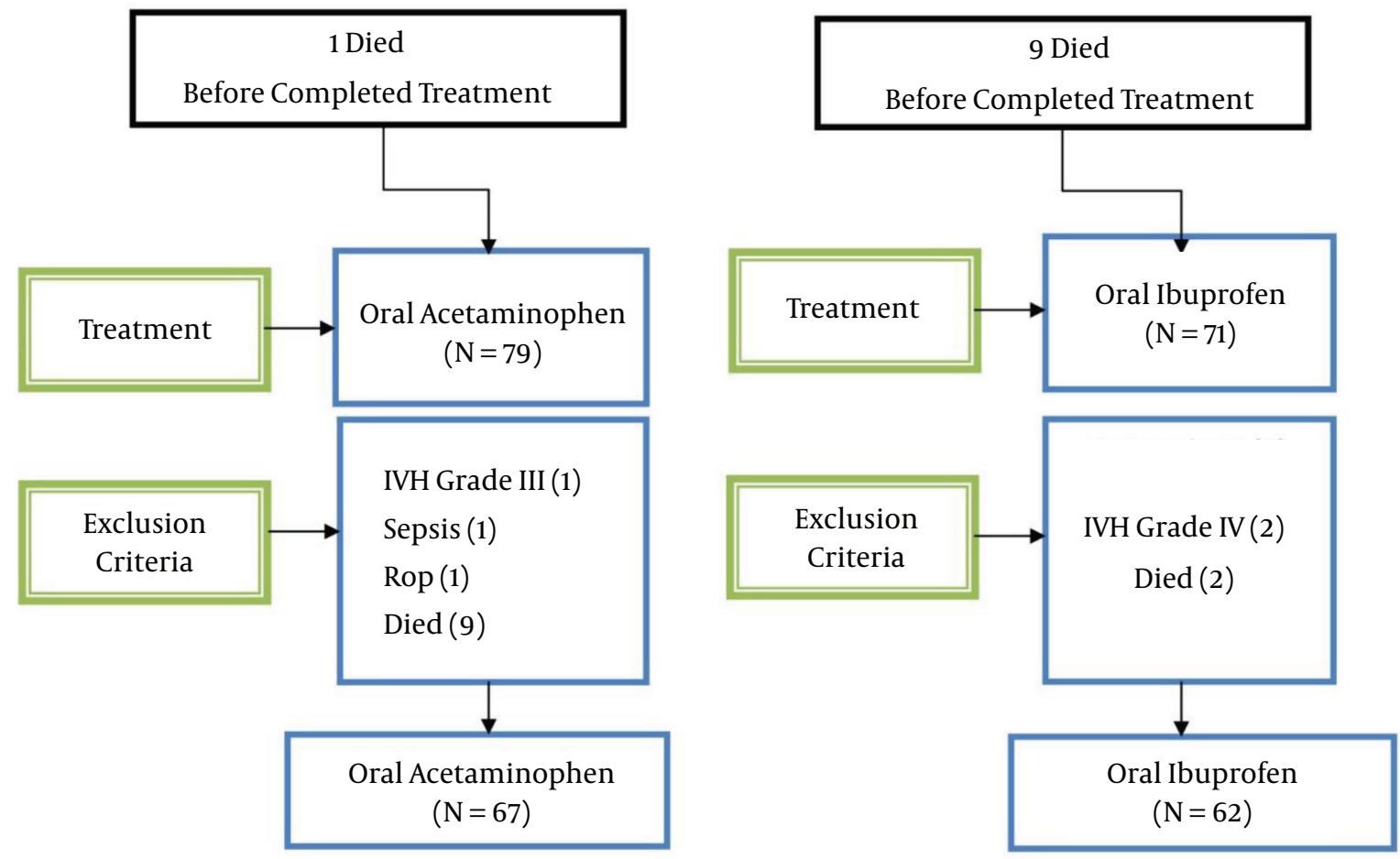

Figure 1. Study Flow Chart

No significant difference was observed clinically between the two groups in baseline. The clinically characteristic findings of the preterm infants are summarized in Table 1 .

After the first course of treatment, PDA was completely closed in 55 (82.1\%) infants of the Acetaminophen group compared with 47 (75.8\%) of the Ibuprofen group and there was no significant difference between the two treatments $(\mathrm{P}=0.381)$. In oral Ibuprofen group, fifteen $(24.2 \%)$ patients required a second course of drug therapy compared with twelve (17.9\%) patients in the oral Acetaminophen group.

After the second course of the drugs, closure rates were $50 \%$ (six of twelve patients) in the Acetaminophen group compared with $73.3 \%$ (eleven of seventeen patients) in the Ibuprofen group, and there was no significant difference between them $(\mathrm{P}=0.212)$.

Finally, closure rates after the two courses of treatment were $91 \%$ in the oral Acetaminophen group and $90.3 \%$ in the oral Ibuprofen group (Table 2).
Table 1. Clinical Characteristic ${ }^{a}$

\begin{tabular}{lccc}
\hline Characteristics & Acetaminophen & Ibuprofen & P Value \\
\hline Gestational age, wk & $31.53(2.31)$ & $31.7(2.24)$ & 0.69 \\
\hline Age, d & $2.85(1.28)$ & $3.42(2.12)$ & 0.098 \\
\hline Birth weight, Kg & $1646.26(59.14)$ & $1642.62(58.46)$ & 0.965 \\
\hline Gender, No. (\%) & & & \\
\hline \multicolumn{1}{c}{ Female } & $31(46.3)$ & $29(46.8)$ & 0.954 \\
\hline \multicolumn{1}{c}{ Male } & $36(53.7)$ & $33(53.2)$ & - \\
\hline $\begin{array}{l}\text { Normal vaginal } \\
\text { delivery (NVD), No. (\%) }\end{array}$ & $20(30.3)$ & $15(24.2)$ & 0.438 \\
\hline Respiratory score, unit & $5.28(2.04)$ & $5.22(1.75)$ & 0.864 \\
\hline \begin{tabular}{l} 
Surfactante, No. (\%) \\
\hline
\end{tabular} & $37(55.2)$ & $29(46.8)$ & 0.337 \\
\hline
\end{tabular}

${ }^{\mathrm{a}}$ Values are expressed as mean (SD) unless otherwise indicated.

\section{Discussion}

Ductal constrict was stimulated by the rapid postnatal increase in arterial oxygen tension and a decrease in va- 
Table 2. Outcomes According to Each Treatment ${ }^{a}$

\begin{tabular}{|c|c|c|c|}
\hline & Acetaminophen $^{\text {b }}$ & Ibuprofen ${ }^{c}$ & P Value \\
\hline $\begin{array}{l}\text { PDA closure rate after } \\
\text { the first course }\end{array}$ & $55(82.1)$ & $45(75.8)$ & 0.381 \\
\hline $\begin{array}{l}\text { PDA closure rate after } \\
\text { the second course }\end{array}$ & $6(50)$ & $11(73.3)$ & 0.212 \\
\hline Total PDA closure rate & $61(91)$ & $56(90.3)$ & 0.885 \\
\hline
\end{tabular}

${ }^{\mathrm{a}}$ Values are expressed as No. (\%)

${ }^{\mathrm{b}} \mathrm{n}=67$.

${ }^{c} \mathrm{n}=62$.

sodilators including prostaglandin E2 (9).

Prostaglandin synthetase has two different activities including cyclooxygenase and peroxidase. Acetaminophen inhibits prostaglandin synthesis at the peroxides' segment (7) while Ibuprofen is cyclooxygenase inhibitor (10).

Some studies have been conducted on Acetaminophen treatment of PDA in preterm infants when Ibuprofen was not effective or contraindicated.

Hammerman et al. for the first time, showed that oral Acetaminophen was effective in five patients with large, hemodynamically significant PDA, that either failed or had contraindications to Ibuprofen therapy. Ductal closure was achieved in all treated infants (8).

Also a series of eight preterm neonates, treated with Acetaminophen for a significant PDA because of contraindications to Ibuprofen were reported by Terrin (11). Acetaminophen as the first choice of treatment of PDA was used in six preterm infants, five infants were successfully treated (12).

Ibuprofen and Acetaminophen was compared in two clinical trials. The trial conducted by Oncel et al. compared the efficacy and safety of oral Acetaminophen and oral Ibuprofen for the closure of PDA in 90 preterm infants with a gestational age less than or equal to thirty weeks of gestation. After the first course of treatment, PDA closed in $77.5 \%$ (31 of 45 patients) of the infants assigned to the oral Ibuprofen group vs. $72.5 \%$ (29 of 45 patients) in the oral Acetaminophen group $(\mathrm{P}=0.6)(13)$.

The second study was done by Dang et al. comparing oral Acetaminophen with Ibuprofen in treatment of 160 preterm PDA infants. The results demonstrated no significant difference between Acetaminophen and Ibuprofen (14).

Recent Small case series have suggested that acetaminophen may be an alternative cyclooxygenase inhibitor for PDA management, but the role of this agent in management of preterm infants with PDA remains to be determined. As the two aforementioned studies sug- gested, in order to generalize their conclusions, it is necessary to run randomized analysis from a multiple center.

There are only two articles comparing oral Ibuprofen and oral Acetaminophen. The first has been performed in Turkey, enrolling neonates $<30$ weeks and a same study done in China on neonates $<34$ weeks.

In contrast, we enrolled neonates $<37$ weeks. Closure rates of PDA in Oncel et al. trial were 72.5\% (Acetaminophen group) and 77.5\% (Ibuprofen group) (13). Furthermore, closure rates were $81.2 \%$ (Acetaminophen group) and $78.8 \%$ (Ibuprofen group) in Dang et al. trial (14).

Our findings showed closure rates of $82.1 \%$ (Acetaminophen group) and $75.8 \%$ (Ibuprofen group). We found a similar responsiveness of PDA to both drugs. This finding was compatible to those in Turkey and China trials. Thus, our study supports their results and demonstrated that oral Acetaminophen and Ibuprofen are effective similarly for the closure of PDA with one and two courses of treatment.

In addition, the results clearly show that both drugs are well-tolerated and safe, and have no significant difference regarding the complications (bleeding, especially gastrointestinal bleeding, NEC, IVH, liver or renal dysfunction, ROP and hyperbilirubinemia).

This study had several limitations; firstly, PDA of infants may spontaneously be closed by the time, therefore daily echocardiography and a clinical trial with control group was necessary. Secondly, the trial was not completely blinded because of the different daily doses of Acetaminophen.

\subsection{Conclusion}

Oral Ibuprofen can effectively close PDA but is unfortunately associated with some adverse effects limiting its utility thus we studied an alternative drug with similar efficacy and less adverse effects and contraindication.

On the basis of identical efficacy of Ibuprofen and Acetaminophen and higher safety of Acetaminophen it is recommended to use Acetaminophen as the drug of first choice.

Although we have demonstrated that Acetaminophen may be utilized as the drug of choice for PDA in preterm infants with good efficacy, further studies are warranted.

\section{Footnote}

Authors' Contribution: Mohammad Mehdi Bagheri, concept, design and critical revision of the manuscript; Pedram Niknafs, concept, design and critical revision of the manuscript; Fatemeh Sabsevari, acquisition of data, data analysis, data, interpretation and drafting of the 
manuscript; Bahareh Bahman Bijari, critical revision of the manuscript; Elahe Noroozi, Mohammad Hosein Torabi, design and critical revision of the manuscript; Hamid Mossavi, critical revision of the manuscript.

\section{References}

1. Reller MD, Rice MJ, McDonald RW. Review of studies evaluating ductal patency in the premature infant.J Pediatr. 1993;122(6):S59-62. doi: 10.1016/s0022-3476(09)90044-0.

2. Schmidt B, Roberts RS, Fanaroff A, Davis P, Kirpalani HM, Nwaesei $C$, et al. Indomethacin prophylaxis, patent ductus arteriosus, and the risk of bronchopulmonary dysplasia: further analyses from the Trial of Indomethacin Prophylaxis in Preterms (TIPP). J Pediatr. 2006;148(6):730-4. doi: 10.1016/j.jpeds.2006.01.047. [PubMed: 16769377].

3. Benitz WE. Treatment of persistent patent ductus arteriosus in preterm infants: time to accept the null hypothesis?. J Perinatol. 2010;30(4):241-52. doi: 10.1038/jp.2010.3. [PubMed: 20182439].

4. Demirel G, Erdeve O, Dilmen U. Pharmacological Management of PDA: oral versus intravenous medications. Curr Clin Pharmacol. 2012;7(4):263-70. [PubMed: 22794156].

5. Erdeve O, Yurttutan S, Altug N, Ozdemir R, Gokmen T, Dilmen U, et al. Oral versus intravenous ibuprofen for patent ductus arteriosus closure: a randomised controlled trial in extremely low birthweight infants. Arch Dis Child Fetal Neonatal Ed. 2012;97(4):F279-83. doi:10.1136/archdischild-2011-300532. [PubMed: 22147286].

6. Zecca E, Romagnoli C, De Carolis MP, Costa S, Marra R, De Luca D. Does Ibuprofen increase neonatal hyperbilirubinemia?. Pediatrics. 2009;124(2):480-4. doi: 10.1542/peds.2008-2433. [PubMed: 19620202].
7. Lucas R, Warner TD, Vojnovic I, Mitchell JA. Cellular mechanisms of acetaminophen: role of cyclo-oxygenase. FASEB J. 2005;19(6):635-7. doi: 10.1096/fj.04-2437fje. [PubMed:15705740]

8. Hammerman C, Bin-Nun A, Markovitch E, Schimmel MS, Kaplan M, Fink D. Ductal closure with paracetamol: a surprising new approach to patent ductus arteriosus treatment. Pediatrics. 2011;128(6):e1618-21.

9. Hamrick SE, Hansmann G. Patent ductus arteriosus of the preterm infant. Pediatrics. 2010;125(5):1020-30. doi: 10.1542/peds.2009-3506. [PubMed: 20421261].

10. Pourarian S, Rezaie M, Amoozgar H, Shakiba AM, Edraki MR, Mehdizadegan N. High-Dose Oral Ibuprofen in Treatment of Patent Ductus Arteriosus in Full-Term Neonates. J Pediatr. 2015;25(4):e2005. .

11. Terrin G, Conte F, Scipione A, Bacchio E, Conti MG, Ferro R, et al. Efficacy of paracetamol for the treatment of patent ductus arteriosus in preterm neonates. Ital J Pediatr. 2014;40(1):21. doi: 10.1186/1824-728840-21. [PubMed: 24555510].

12. Yurttutan S, Oncel MY, Arayici S, Uras N, Altug N, Erdeve O, et al. A different first-choice drug in the medical management of patent ductus arteriosus: oral paracetamol. J Matern Fetal Neonatal Med. 2013;26(8):825-7. doi: 10.3109/14767058.2012.755162. [PubMed: 23205872].

13. Oncel MY, Yurttutan S, Erdeve O, Uras N, Altug N, Oguz SS, et al. Oral paracetamol versus oral ibuprofen in the management of patent ductus arteriosus in preterm infants: a randomized controlled trial. $J P e$ diatr. 2014;164(3):510-4 e1. doi: 10.1016/j.jpeds.2013.11.008. [PubMed: 24359938].

14. Dang D, Wang D, Zhang C, Zhou W, Zhou Q, Wu H. Comparison of oral paracetamol versus ibuprofen in premature infants with patent ductus arteriosus: a randomized controlled trial. PLoS One. 2013;8(11):e77888. 